Article

\title{
Design of Experiment for the Optimization of Pesticide Removal from Wastewater by Photo-Electrochemical Oxidation with $\mathrm{TiO}_{2}$ Nanotubes
}

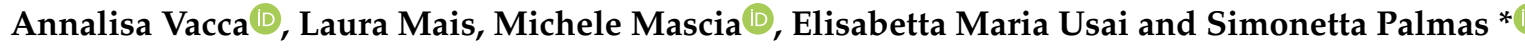 \\ Dipartimento di Ingegneria Meccanica, Chimica, e dei Materiali (DIMCM), Università degli Studi di Cagliari, \\ via Marengo 2, 09123 Cagliari, Italy; annalisa.vacca@dimcm.unica.it (A.V.); 1.mais@dimcm.unica.it (L.M.); \\ michele.mascia@unica.it (M.M.); elisabetta.usai@unica.it (E.M.U.) \\ * Correspondence: simonetta.palmas@dimcm.unica.it
}

Received: 24 March 2020; Accepted: 3 May 2020; Published: 7 May 2020

\begin{abstract}
The Design of Experiment (DoE) technique has been used to investigate the photo-electrochemical removal of diuron (DRN) from wastewater. The process is carried out in a photo-electrochemical flow reactor, in which titania nanotubular electrode is irradiated with a simulated solar light. Different operative conditions have been investigated, in a planned $2^{3}$ full factorial design in which imposed current density, flow rate and initial concentration have been varied at two levels. The removal process of DRN was investigated in terms of specific removal rate $(K)$ and cell voltage $(E)$, which were assumed as objective functions: the results show that the applied current has a paramount effect on both of the objective functions. From the analyses of the intermediates, it appears that the investigated parameters may exert different effects on the distribution of the reaction products: the initial concentration of diuron and the electrode potential seem to play a more important role, in this case.
\end{abstract}

Keywords: advanced oxidation process; photo-electrochemical degradation; diuron; design of experiments; $\mathrm{TiO}_{2}$ nanotubes

\section{Introduction}

Electrochemical advanced oxidation processes (EAOPs) have been widely studied for the treatment of bio-recalcitrant and persistent organic pollutants [1-3], including pesticides [4,5], pharmaceuticals and textile dyes [6-8], to mention a few. EAOPs are based on the generation of hydroxyl radicals $(\cdot \mathrm{OH})$, which are non-selective and powerful oxidizing species exploitable as pre-treatment to improve the biodegradability, or as post treatment to remove traces of organic pollutants $[9,10]$. Among the EAOPs proposed for the treatment of wastewaters containing organic pollutants, photo-electrocatalysis (PEC) has been successfully applied, due to its high efficiency in mild conditions [11-13]. The photo-electrocatalytic technique combines electrolytic and photocatalytic processes, in which the application of an electrical potential bias assists the separation of the electron-hole pairs generated during the photocatalytic process, reducing the recombination of charges and in turn, increasing their lifetime [14]. The operating costs could be markedly reduced by using solar radiation $[15,16]$.

Over the last 15 years, an increasing number of papers has been published on PEC, applied to the removal of a large variety of organic pollutants, most of them dyes and, to a lesser extent, chemicals and drugs, and to the treatment of real wastewaters $[17,18]$. In most cases, $\mathrm{TiO}_{2}$-based materials have 
been used as photoanodes because they offer important advantages as a result of their non-toxic, optical, low-cost and biocompatibility properties $[19,20]$.

Due to the combined nature of PEC processes, both electrical and photochemical parameters may influence the process. Thus, for example, (i) electrochemical parameters, such as applied current and cell potential, (ii) characteristics of the light source, in terms of wavelength and intensity of the irradiation light flow, (iii) physical properties of the semiconductor material, such as light absorption coefficient, band structure (band gap, band edges and Fermi level), along with (iv) specific operating conditions, such as electrolyte composition and flow rate, $\mathrm{pH}$, and temperature, can be crucial in determining the final performance of the process [21].

The study of such systems, where a wide number of variables may be influent, can be effectively performed by using the design of experiment (DoE) technique: excellent statistical packages exist to help in data analysis, such as Statistica, Minitab, Action Stat, Design Expert [22]. Compared to the classical experimental optimization methods, which are characterized by a "single process variable at a time" this technique represents a very useful tool which allows to evaluate the effects of multiple variables, with statistical accuracy in response, obtaining reliable results while saving time and resources [22].

A deep description of the DoE technique is out of the aim of this work, though we may suggest specific literature for it [23,24]. However, some detail can be given on this method, to illustrate its basic principles, while specific information on its application to this experimental work is reported in the next section. Following this technique, a minimum number $(n)$ of experiments $\left(n=L^{p}\right)$ can be planned in which the $p$ parameters are varied, at two or more levels $(L)$, in a programmed and rational way, and their effects on selected objective functions are evaluated. Although the reduced factorial design is often used, the complete factorial design becomes necessary when the influence of the variables has to be assessed, without running the risk of excluding factors or interactions that may be important [23].

In the simplest case, a two-full factorial design (2FFD) can be used, in which the parameters are varied at two levels, so that the minimum number of requested experiments is $n=2^{p}$.

A 2FFD has been adopted in the present case to study the process of removal of diuron (DRN), (3-(3,4-Dichlorophenyl)-1,1-dimethylurea), a persistent pesticide, belonging to the sub-class of herbicides, often detected in aqueous solutions coming from agriculture wastewater. A photo-electrochemical reactor was used, which operated in continuous mode, equipped with $\mathrm{TiO}_{2}$ nanotubular anode, irradiated by a solar simulator, through a quartz window. The applied electrical current, the electrolyte flow rate and the initial reactant concentration, were selected among the possible parameters which may influence the reactant removal rate, and the cell potential, which were assumed as objective function. The fate of the intermediates originated during the degradation process has also been considered.

\section{Results and Discussion}

\subsection{DoE Model Description}

The 2FFD was applied to perform galvanostatic photoelectrochemical degradation tests and determine the interaction between different selected factors. On the bases of previous work carried out in our laboratory [7], electrolyte flow rate $(Q)$, along with applied current $(I)$ and initial reactant concentration $\left(C_{0}\right)$, have been selected as control parameters which could influence the process of the reactant removal, while the electrode was irradiated by a constant light power, generated by the solar simulator. Aqueous solutions of DRN were used to simulate the wastewater: the pollutant removal process was carried out under galvanostatic conditions and the runs were made in double. The experimental campaign has been planned by the DoE technique under experimental conditions as resumed in Table 1. The DRN removal process was investigated in terms of specific removal rate $(K)$ and cell voltage $(E)$, which were assumed as objective functions $(\mathrm{OFs})$. Single and combined effects on these OFs were evaluated while $Q, I$ and $C_{0}$ were varied at two levels as reported in Table 1 . In order to derive reliable estimation of the relative size of the effects, coded levels of the parameters have 
been used: the conversion of each original variable, $A_{\mathrm{i}}$, to the coded one, $x_{\mathrm{i}}$, was performed using the following formula:

$$
x=\left(A-A_{0}\right) / \text { step }
$$

where $A_{0}=\left(A_{\max }+A_{\min }\right) / 2$ and step $=\left(A_{\max }-A_{\min }\right) / 2$ so that the high and low levels of $x$ are represented by +1 and -1 , respectively.

Table 1. Values of the $K$ and $E$ measured in the eight runs of the DoE. Averaged values and the related standard deviation (SD) are evaluated for data repeated twice.

\begin{tabular}{ccccccccccc}
\hline & \multicolumn{3}{c}{ Coded Levels } & \multicolumn{3}{c}{ Real Values of Parameters } & \multicolumn{3}{c}{ Observed Responses } \\
\hline \multirow{2}{*}{ Run } & $\mathbf{x}_{\mathbf{1}}$ & $\mathbf{x}_{\mathbf{2}}$ & $\mathbf{x}_{\mathbf{3}}$ & $\begin{array}{c}\mathbf{I} \\
{[\mathbf{m A}]}\end{array}$ & $\begin{array}{c}\mathbf{Q} \\
{\left[\mathbf{m L} \mathbf{~ m i n}^{-1}\right]}\end{array}$ & $\begin{array}{c}\mathbf{C}_{\mathbf{0}} \\
{[\mathbf{p p m}]}\end{array}$ & $\begin{array}{c}\mathbf{K} \times \mathbf{1 0}^{\mathbf{4}} \\
{\left[\mathbf{m i n}^{-1}\right]}\end{array}$ & $\begin{array}{c}\text { SD } \\
\mathbf{K}\end{array}$ & $\begin{array}{c}\text { E } \\
{[\mathbf{V}]}\end{array}$ & SD E \\
\hline 1 & -1 & -1 & -1 & 0.50 & 60 & 10 & 15.0 & 1.41 & 0.6 & 0.053 \\
2 & 1 & -1 & -1 & 1.25 & 60 & 10 & 21.0 & 1.41 & 2.3 & 0.074 \\
3 & -1 & 1 & -1 & 0.50 & 200 & 10 & 17.5 & 0.71 & 0.2 & 0.018 \\
4 & 1 & 1 & -1 & 1.25 & 200 & 10 & 33.0 & 1.41 & 2.1 & 0.057 \\
5 & -1 & -1 & 1 & 0.50 & 60 & 20 & 19.0 & 1.41 & 0.3 & 0.025 \\
6 & 1 & -1 & 1 & 1.25 & 60 & 20 & 28.0 & 0.00 & 1.5 & 0.035 \\
7 & -1 & 1 & 1 & 0.50 & 200 & 20 & 21.5 & 2.12 & 0.4 & 0.035 \\
8 & 1 & 1 & 1 & 1.25 & 200 & 20 & 27.0 & 0.00 & 0.9 & 0.092 \\
\hline
\end{tabular}

Table 1 reports the combination of the different coded parameters to be set in the eight runs planned in a $2^{3}$ full factorial design, while the following relation is adopted to evaluate the effects of the $i$-th parameter on each objective function:

$$
e_{i}=\bar{Y}^{+}-\bar{Y}^{-}=\left(\sum Y_{i}^{+}-\sum Y_{i}^{-}\right) / 4
$$

where $Y^{+}$and $Y^{-}$represent the mean of the values of the responses obtained from runs in which the $i$-th parameter was set at the highest $(+1)$ and lowest $(-1)$ levels, respectively.

Replication of the experiments allowed us to evaluate the standard error $(S E)$ and the standard deviation $(S D)$ in accordance with the following relations:

$$
\begin{gathered}
S D=\sqrt{\sum\left(X-X_{m}\right)^{2} /(N-1)} \\
S E=\mathrm{SD} / \sqrt{\mathrm{N}}
\end{gathered}
$$

Finally, the relation between variables $x_{i}$ and the response $Y_{j}$ was modeled as:

$$
Y_{j}=\beta_{0}+\sum_{j=1}^{k} \beta_{j} x_{j}+\sum_{i<j} \sum \beta_{i j} x_{i} x_{j}
$$

where $Y$ corresponds to the response variable, $x$ represents the influent factors, $\beta_{0}$ is the mean value of response variable, $\beta_{j}$ and $\beta_{i j}$ represent the linear and the interaction coefficients, respectively, estimated from the least squares method.

\subsection{Degradation Experiments}

The photo-electrocatalytic activity of the samples was firstly tested by a preliminary run performed in a beaker cell, in the dark, at open circuit for the first $60 \mathrm{~min}$; after that, galvanostatic conditions were imposed $(1.25 \mathrm{~mA}, 1 \mathrm{~h})$, and finally, the light of the xenon lamp was switched on. The electro- and photo-electroactivity of the sample is clearly shown from the increase of about $60 \%$ in the slope of the trend with time of the reactant concentration (Figure 1), recorded during this test. 


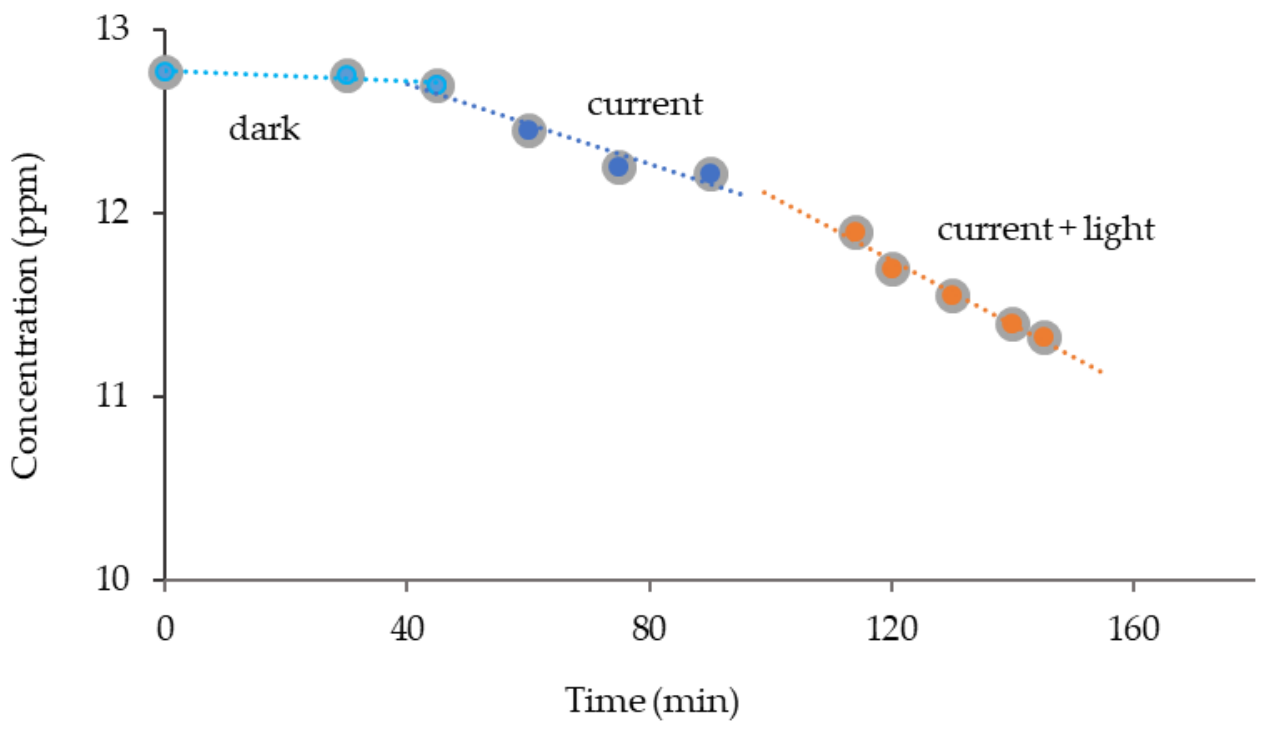

Figure 1. Trend of diuron (DRN) concentration during a preliminary run performed under different conditions: adsorption in the dark; galvanostatic electrolysis $(I=1.25 \mathrm{~mA})$ in the dark, and under irradiation.

Contrastingly, the effect of possible adsorption of DRN on the electrode surface was negligible; of note, working at $\mathrm{pH}=5.5-6$ as in the present case, a poor interaction between the electrode surface (iso-electrical point of $\mathrm{TiO}_{2}$ is at $\mathrm{pH}=4-6$ ) and the molecule of $\mathrm{DRN}$ ( $\mathrm{pKa}=3.7$ ) could justify this trend [25]. Anyway, each run was preceded by a period of $30 \mathrm{~min}$ in the dark conditions, to allow reaching the adsorption equilibrium on the electrodes' surface.

The rest of the experimental campaign was performed in a flow cell in which it was possible to operate at different electrolyte flow rates: this parameter is of great importance when we deal with heterogeneous reactions, such as the one examined in the present work.

Figure 2 shows the trend of the first series of data, as a function of the supplied electrical charge $q$ (Coulomb): the runs have been performed at two levels of applied current (red and blue curves), two electrolyte flow rates (full and dotted lines) and two initial concentration of DRN (full and empty symbols). Depending on the runs, the electrolysis was protracted for a different time, so that the course of the reactions could be compared, the charge supplied being the same.

As can be observed, if one wanted to individuate the best operating conditions, even just under a qualitative point of view, the task would be far from simple, because the effect exerted by one parameter, on a given $\mathrm{OF}$, depends on the values assumed by the other parameters. Just one parameter could not be enough to clarify the convenience of the process: thus, for example, the condition which could have given high initial reaction rate, might not be the optimal in terms of electrode potential and, in turn, of costs.

On these bases, the evaluation of the effectiveness of the process, has been made by means of two OFs: the first-which has to be maximized-was the specific reaction rate of DRN removal $(K)$, and the second - which has to be minimized - was the cell potential $(E)$, which is of crucial importance to identify the reaction mechanism and to take account for the costs of the whole process.

In particular, $K$, was evaluated from the slope of the linear regression curve of data expressed as $\ln \left(C / C_{0}\right)$ vs $t$ : actually, under all the relevant operative conditions, the initial trend of the curves was fitted by a pseudo-first order kinetics. 


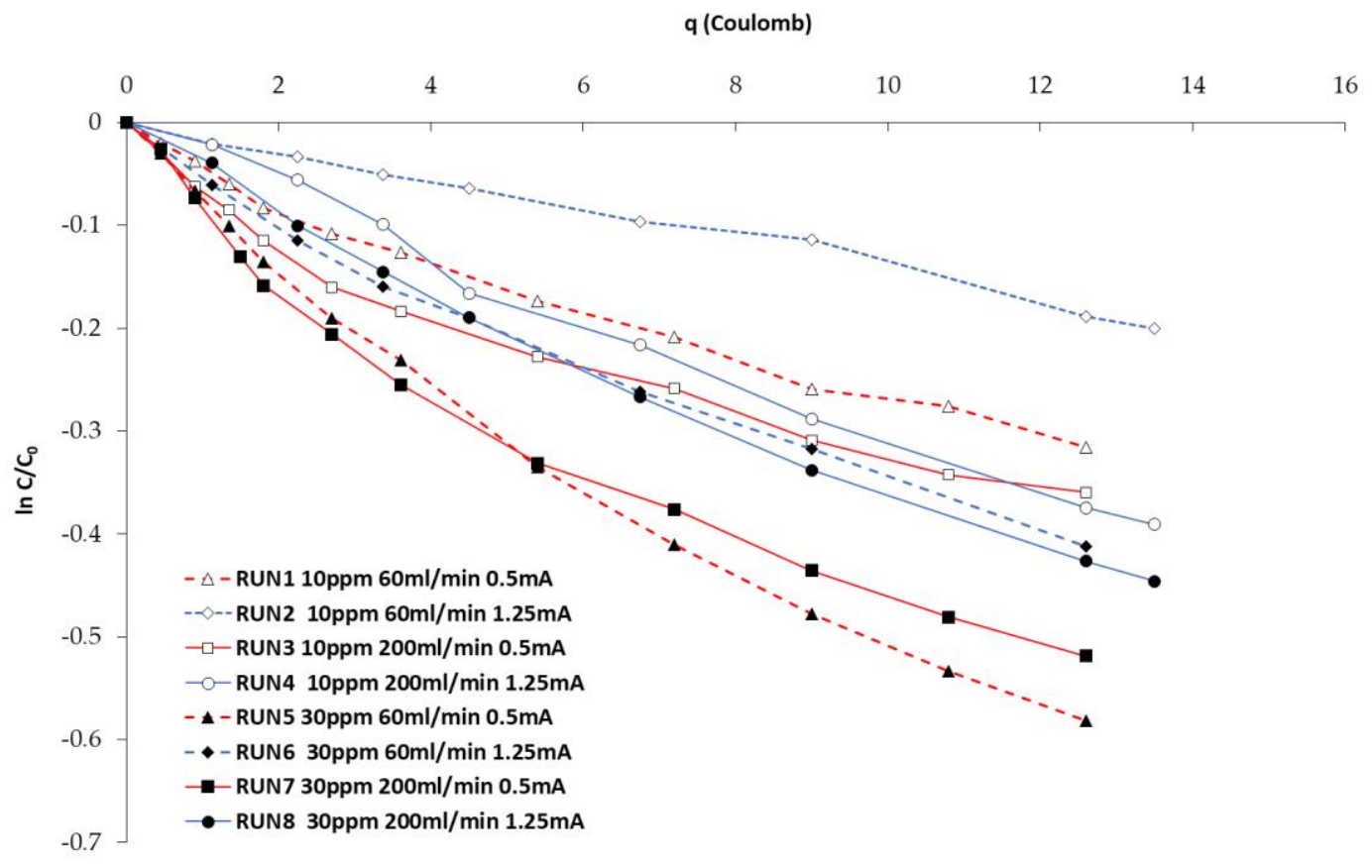

Figure 2. Trend of logarithm of DRN concentration, normalized with respect to its initial concentration, as a function of the electric charge supplied during the galvanostatic electrolyses performed at the irradiated samples, under the different conditions planned in the Design of Experiment (DoE).

As the second OF is concerned, it must be observed that, depending on the applied current, different potentials were established across the electrodes of the cell. Figure 3 shows an example of the potential trend recorded during a run performed at $0.5 \mathrm{~mA}$. As can be observed, after a few minutes of reaction, a constant value was achieved, and this value was assumed for the rest of the DoE analysis. In order to highlight the photo-activity of the sample, in this example, the figure shows the step of potential measured when dark was suddenly made during the run. Of note, without the effect of the light, a higher potential (about $4 \mathrm{~V}$ ) should be needed to sustain the same value of current. Instead, thanks to the activity of the semiconductor material, we are able to gain more than $3 \mathrm{~V}$ in potential, which in turn, results in saving electrical power and cost.

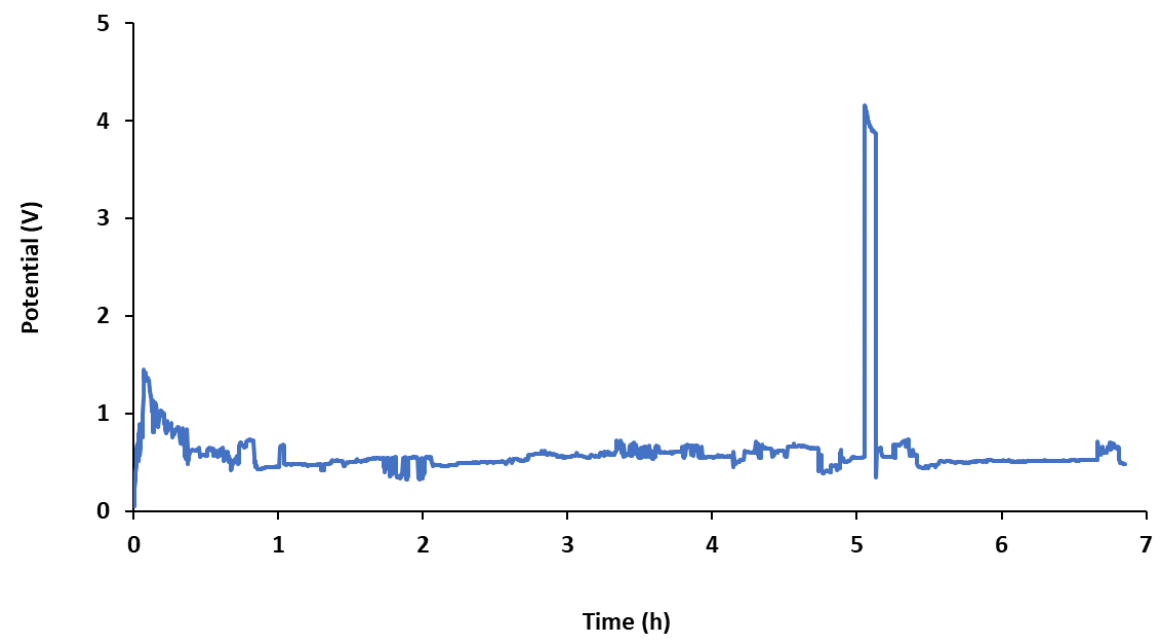

Figure 3. Example of the cell potential trend recorded during a galvanostatic run performed under irradiation and at $0.5 \mathrm{~mA}$ : the figure shows the step of potential measured when dark was suddenly made during the run. 
The values of the two OFs measured in the different conditions are reported in Table 1. As specified in the experimental section, runs were repeated twice, so in Table 1 the average values, as well as the standard deviation (SD) are reported. A comparison of the performance of photo-electrocatalytic systems is not straightforward, because, as pointed out in the introduction, several factors may affect the final result. Instead, a more direct comparison may be made with the results obtained in previous work, carried out in our laboratory with the same system $[7,26]$. Depending on the operative conditions, $K$ values in the range of $6 \times 10^{-4}$ to $9 \times 10^{-3} \mathrm{~min}^{-1}$ have been calculated for the treatment of methyl orange, while in the case of phenol $K$ ranged from $1.1 \times 10^{-3}$ to $6.5 \times 10^{-3} \mathrm{~min}^{-1}$ which confirm that different reactivity of the aromatic compounds may be connected to the different groups linked to the aromatic ring. Indication was also derived about the reactivity of the intermediates: after the initial attack of the molecule, aromatic intermediates react faster $\left(K=1.5 \times 10^{-2} \mathrm{~min}^{-1}\right)$, and finally, the reaction slows down with aliphatic compounds $\left(K=6 \times 10^{-4} \mathrm{~min}^{-1}\right)$.

In the present case, the attention was paid on the evaluation of the possible factors which could be important to determine the final performances. Thus, single and combined effects of the different parameters were evaluated by Equation (2), and compared in Figure $4 \mathrm{a}, \mathrm{b}$ for $K$ and $E$, respectively. We can observe that $I$ has the highest single and positive effect on both the functions (the higher the applied current, the higher $\mathrm{K}$ and $\mathrm{E}$ are measured).

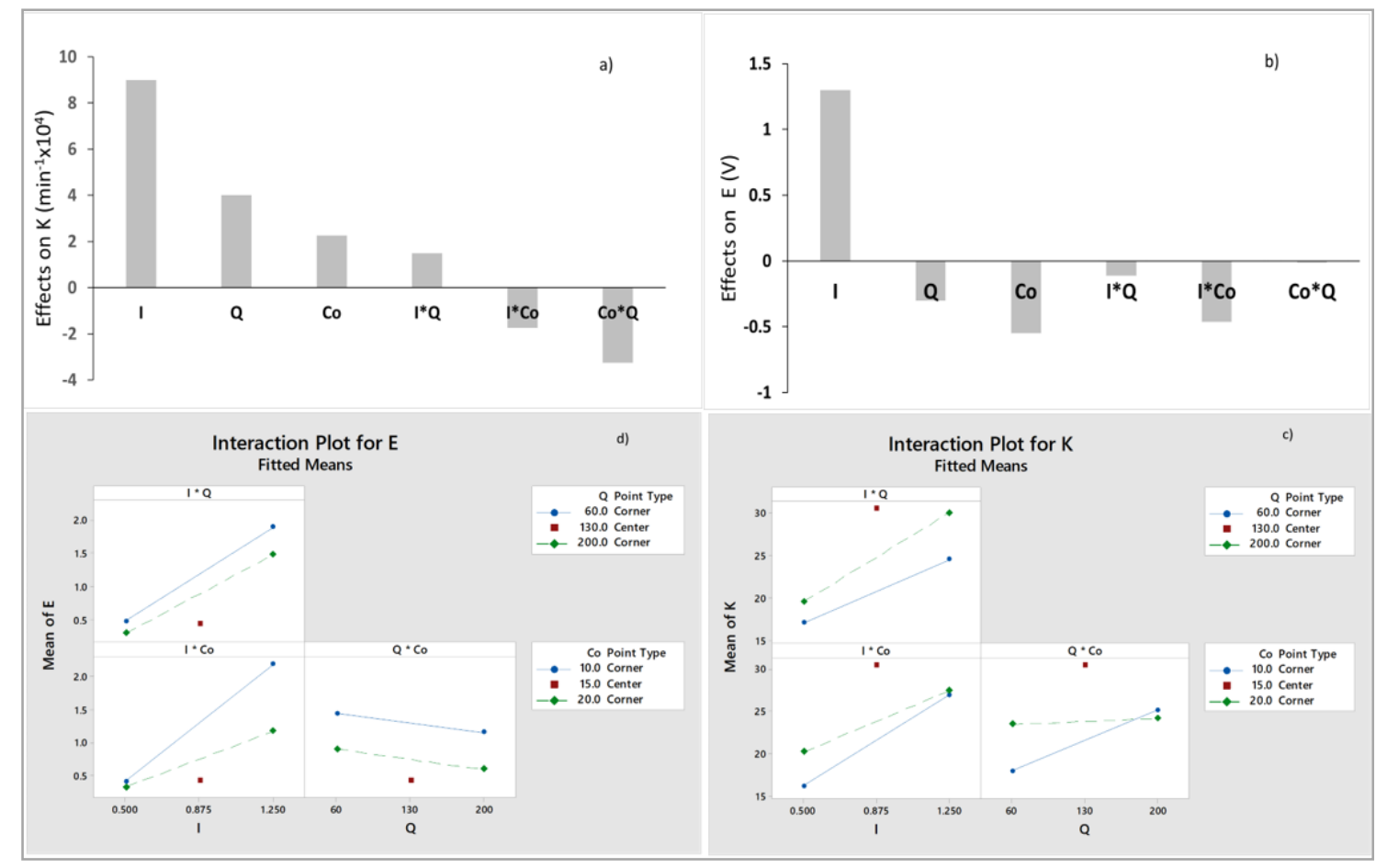

Figure 4. Comparison of single and binary effects of the different parameters on $K$ (panel a) and $E$ (panel $\mathbf{b}$ ). Interaction plots for the binary effects on $K$ (panel c) and $E$ (panel d); the response at the

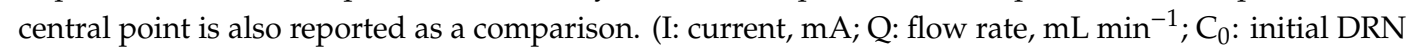
concentration, ppm).

Interaction plots reported in Figure 4c,d, clarify the combined effects among the different couples of parameters: the more parallel the segments, the lower the interaction between the related parameters. Thus, for example, only binary interaction between $I$ and $C_{0}$ is evidenced on $E$, while on $K$ the strongest seems to be the one between $Q$ and $C o$.

The variance analysis (ANOVA) allowed evaluating the significance of all the measured effects, within $95 \%$ of the confidence level. The related Pareto charts are presented in Figure $5 \mathrm{a}, \mathrm{b}$ for $K$ and $E$, respectively. If the effects on $K$ are considered, the single effects of $I$ and $Q$ are effectively influent, 
and just $Q * C_{0}$ appears significant among the binary effects, at the $95 \%$ of confidence level. In the case of $E$, the only significant effect is that of $I$; among the other effects the most influent seems to be the one of the concentration, but it becomes significant only if the confidence level decreases at $93 \%$.

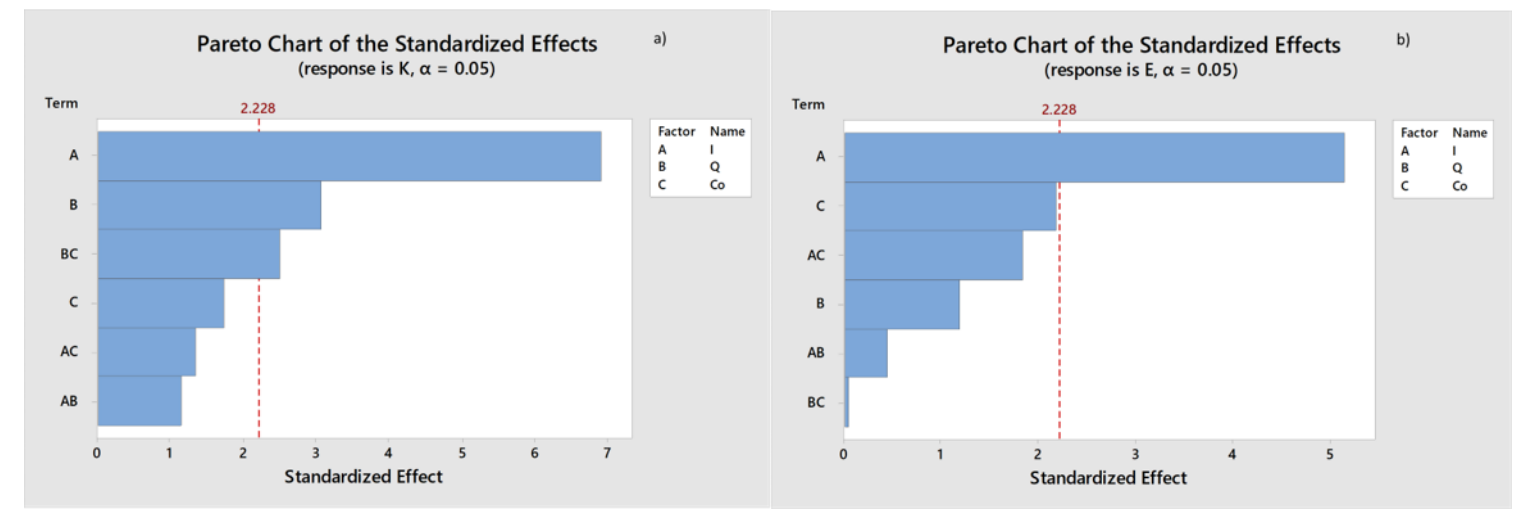

Figure 5. Pareto charts of standardized effects on $K$ (panel a) and $E$ (panel b) related to a significance level of $95 \%$. (I, Q, $\mathrm{C}_{0}$ stand for applied current, electrolyte flow rate and initial concentration, respectively).

Quantification of the different effects allowed deriving the final models which describe the dependence of $K$, and $E$ on the three investigated parameters, as a first-order equations (Equations (6) and (7), respectively):

$$
\begin{gathered}
K\left(\mathrm{~min}^{-1} \times 10^{4}\right)=-4.55+11.46 \mathrm{I}+0.0768 \mathrm{Q}+1.179 \mathrm{C}_{0}+0.0214 \mathrm{I} * \mathrm{Q}-0.350 \mathrm{I} * \mathrm{C}_{0}-0.00464 \mathrm{Q} * \mathrm{C}_{0} \\
E(\mathrm{~V})=-0.83+2.896 \mathrm{I}-0.00027 \mathrm{Q}+0.0398 \mathrm{C}_{0}-0.00161 \mathrm{I} * \mathrm{Q}-0.0925 \mathrm{I} * \mathrm{C}_{0}-0.000018 \mathrm{Q} * \mathrm{C}_{0}
\end{gathered}
$$

These linear models describe the response surfaces of the two OFs as planes, possibly twisted, due to the presence of the interaction factors. However, possible deviations from linearity are indicated by the responses at the central point $\left(\mathrm{I}=0.87 \mathrm{~mA} ; \mathrm{Q}=135 \mathrm{~mL} \mathrm{~min}^{-1} ; \mathrm{C}_{0}=15 \mathrm{ppm}\right)$, reported in the interaction plots (Figure $4 \mathrm{c}, \mathrm{d}$ ), which could suggest the need for a higher degree model. Of note, the mean responses at the central point were quite different (higher in the case of $K$, and lower in the case of $E$ ) from the average response of the factors at their low and high levels.

An example of the contour plots and surface diagrams estimated by Minitab software, when the response at the central point is enclosed in the model, is shown in Figure 6.

Although a higher degree model should be used to obtain a more precise description of the relationship between parameters and OFs, the presented data confirm the complexity of the system: a comparison between the graphs immediately indicates that the central zone could be the most convenient in which the combination of the parameters allows for operating with the highest removal rate and the lowest cell potential.

The results of this preliminary analysis have been used to explain the reaction mechanism, through the distribution of reactant and products individuated during the different runs. Moreover, considering that the current resulted one of the most influent parameters, a further run (classified as RUN 9 in the rest of the text) has been performed at higher current $\left(I=2.5 \mathrm{~mA} ; Q=60 \mathrm{~mL} \mathrm{~min}^{-1} ; C_{0}=20 \mathrm{ppm}\right)$, protracted for $7 \mathrm{~h}$, and its occurrence has been monitored in terms of reactant disappearance and product generation. Of note, even if this current was out of the range investigated in the planned DoE, the specific reaction rate experimentally measured for this last run $\left(K=33 \times 10^{-4} \mathrm{~min}^{-1}\right)$ agreed well with that calculated by the model (Equation (6)): $K=32.14 \times 10^{-4} \mathrm{~min}^{-1}$. The same cannot be said for the $E$ value, which was measured around $5.5 \mathrm{~V}$, whereas a quite different value was estimated by the model (Equation (7)) $(\mathrm{E}=2.3 \mathrm{~V})$. Further investigation is still being undertaken to clarify this aspect. 


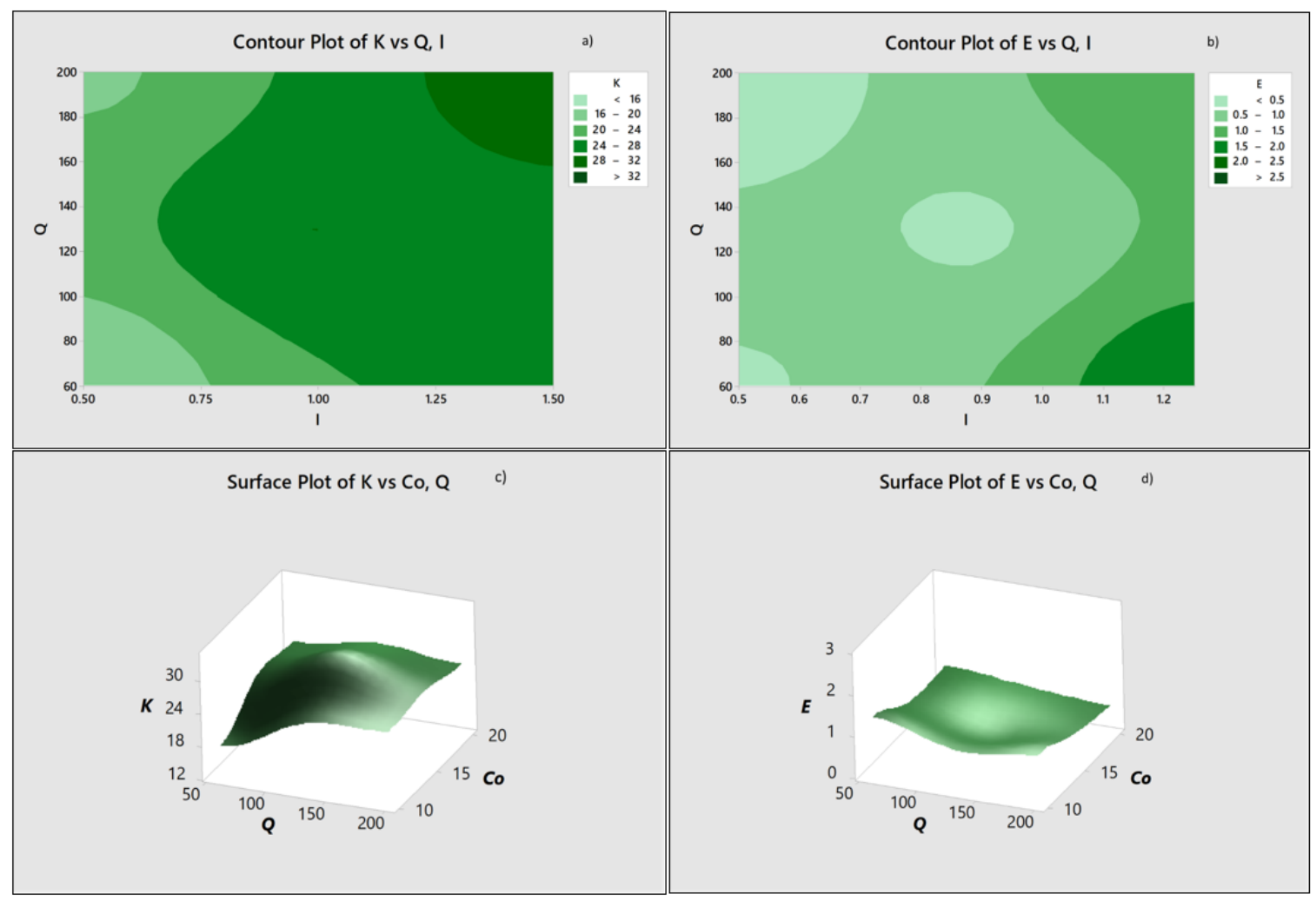

Figure 6. Contour plots and surface plots of $K$ (panel $(\mathbf{a}, \mathbf{c}))$ and $E($ panel $(\mathbf{b}, \mathbf{d}))$, respectively. (I, $\mathrm{Q}, \mathrm{C}_{0}$ stand for applied current, electrolyte flow rate and initial concentration, respectively).

As the reaction products are concerned, the UV analysis allowed for describing the trend with time of the decreasing DRN concentration and the formation of possible aromatics which appeared from the start of the reaction. Figure 7a reports an example of the evolution of the UV spectra of the samples collected during a run performed at low levels of the parameters.

Three peaks are present in the initial solution: p1 at $210 \mathrm{~nm}, \mathrm{p} 2$ at $248 \mathrm{~nm}$ and the third, p3, less revealed at $280 \mathrm{~nm}$ : a detail is zoomed in the inset to better highlight its evolution. Figure $7 \mathrm{~b}$ shows the trend of the height of the peaks, normalized with respect to their initial value, which indicates that, as the reaction proceeds, $\mathrm{p} 1$ and $\mathrm{p} 2$ tend to decrease, but not proportionally, while $\mathrm{p} 3$ increases. This indicates that during the reaction, new products are originated which absorb at wavelengths which partially overlap with $\mathrm{p} 1$ (which in fact decreases less than $\mathrm{p} 2$ ), and with that of $\mathrm{p} 3$ which even increases. This fact was also confirmed by the HPLC analysis. Figure 8 illustrates an example of these measurements made at the wavelength of $280 \mathrm{~nm}$, on samples withdrawn at different reaction times. We can observe the two different peaks at about 8 and $33 \mathrm{~min}$, related to the initial DRN concentration. As the reaction proceeds, the decreasing of the main peak ( $33 \mathrm{~min}$ ) of DRN is observed, as well as, at a low retention time, the appearance of new, as-yet-unidentified peaks, which could be attributed to aromatic compounds partially overlapping that of DRN $(8 \mathrm{~min})$. The comparison between UV spectra and HPLC analyses allowed for monitoring the formation of these aromatic compounds (AR will be used to indicate them in the rest of the discussion), by separating their contribution to $\mathrm{p} 3$ from that of the reactant. 


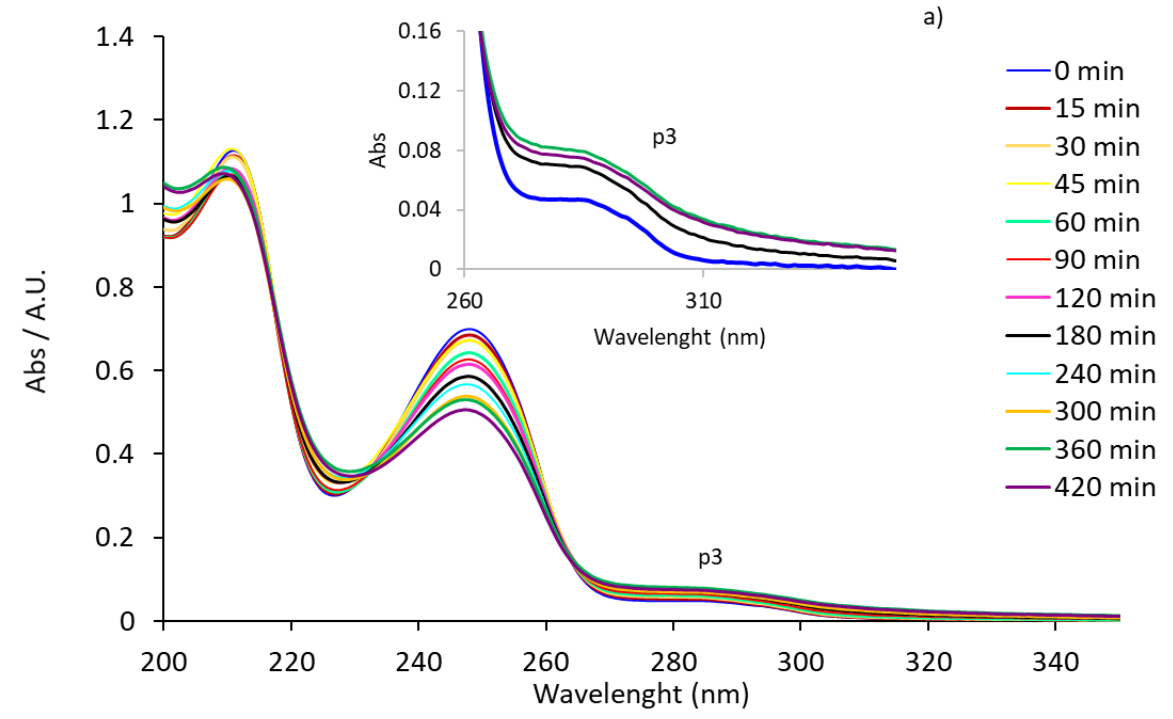

b)

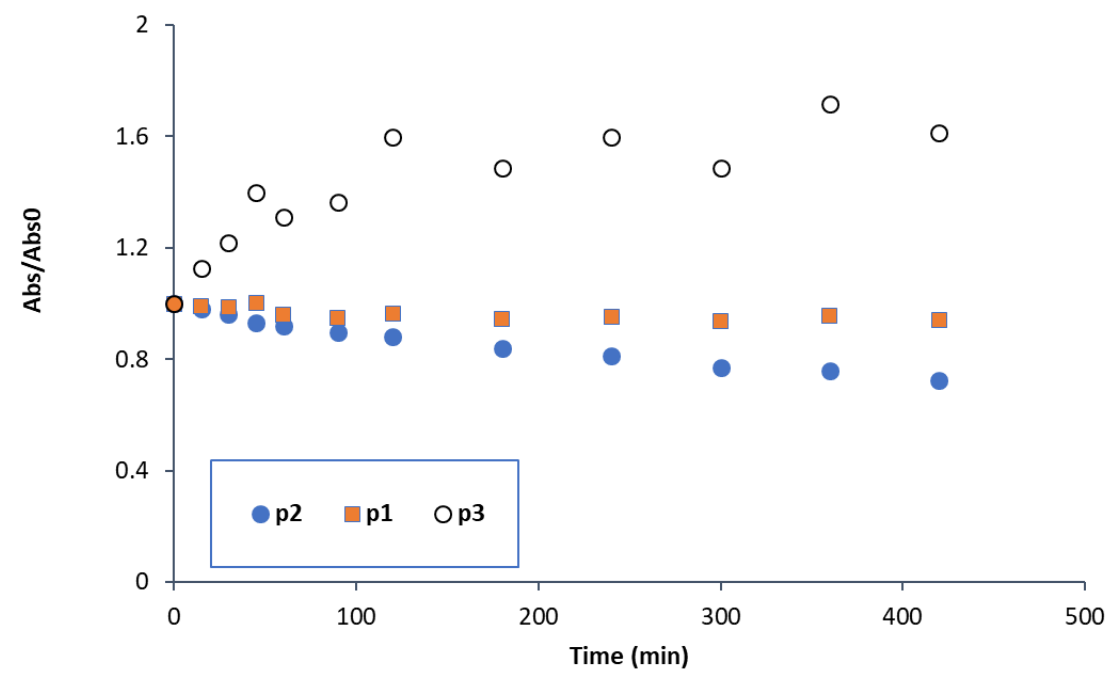

Figure 7. Trend with time of the spectra of absorbance (panel a) and the height of the peaks (panel $\mathbf{b}$ ) p1, p2 and p3, normalized with respect to their initial values obtained for $\mathrm{I}=0.5 \mathrm{~mA}, \mathrm{Q}=60 \mathrm{~mL} \mathrm{~min}^{-1}$ and $C_{0}=10 \mathrm{ppm}$.

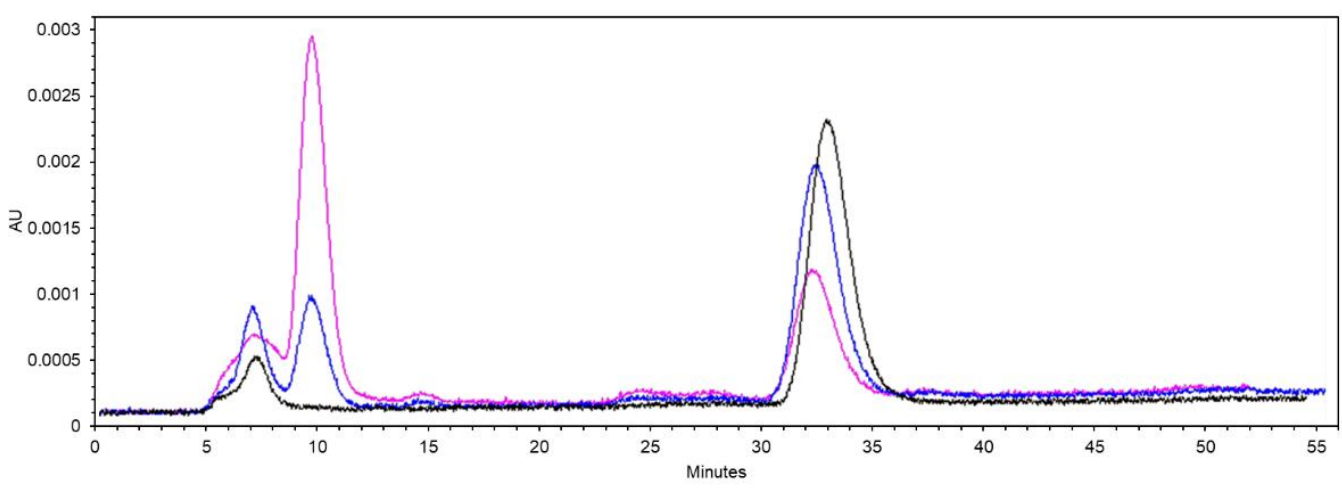

Figure 8. Example of the trend of the HPLC spectra measured at $280 \mathrm{~nm}$, at different times of reaction: $\mathrm{t}=0$ (black curve), $\mathrm{t}=60 \mathrm{~min}$ (blue curve), and $\mathrm{t}=300 \mathrm{~min}$ (pink curve). 
The results of the UV analyses have been elaborated and reported, in arbitrary units, in Figure 9, as a function of the removed DRN: data have initially been grouped, according to the values of applied current. As was expected, the runs with a higher initial DRN concentration give rise to a higher concentration of AR; however, under both the conditions of current, the amounts of AR are comparable. Instead, data indicate that $C_{0}$ could be the discriminant factor in determining the amount of intermediates generated, as well as the level of DRN conversion at which their maximum is obtained. Depending on the conditions, the reaction path is different, and, in turn, the intermediates tend to accumulate differently.
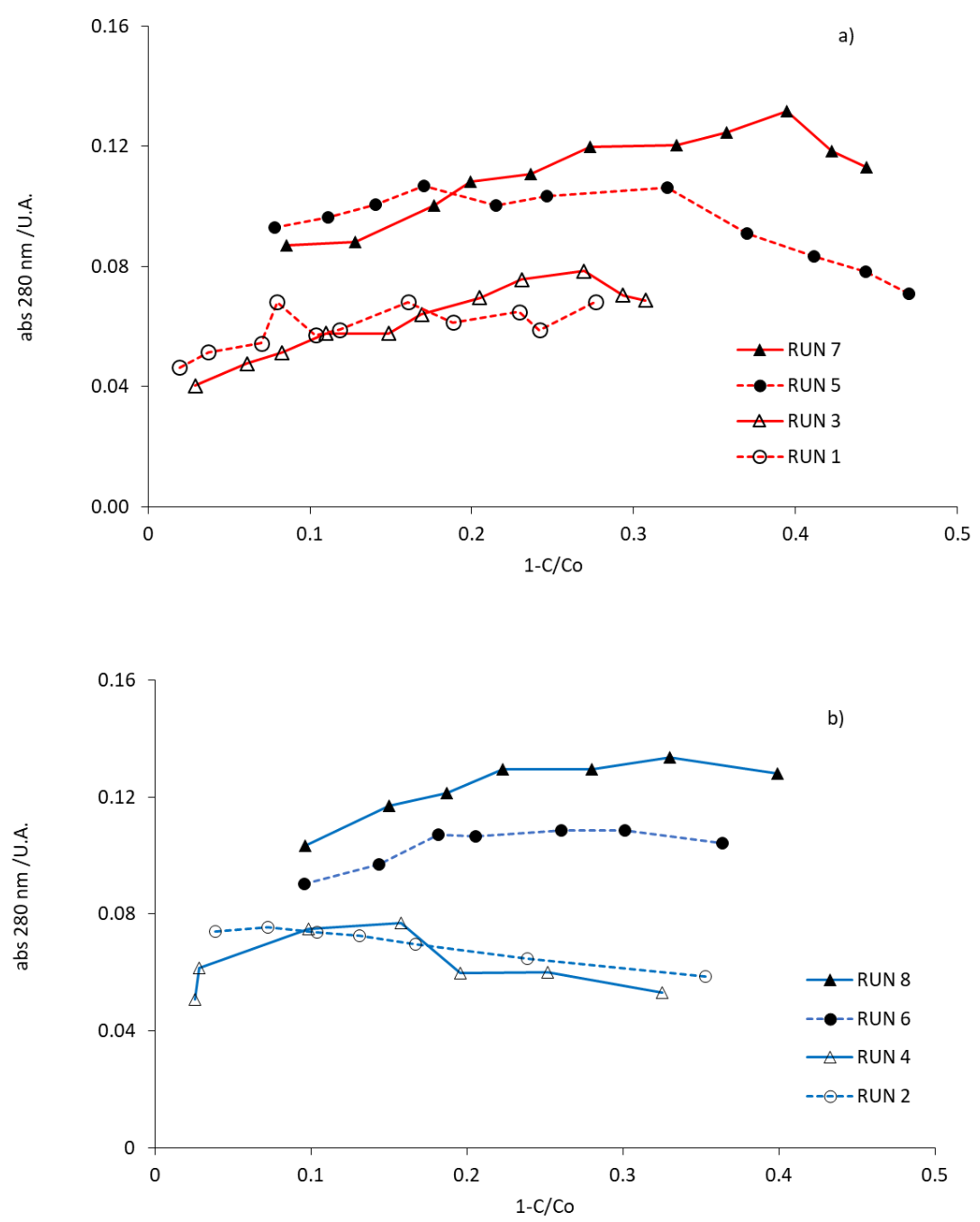

Figure 9. Values of absorbances detected at $280 \mathrm{~nm}$ as a function of the removal of DRN obtained for the eight runs: panel (a) reports the results at $I=0.5 \mathrm{~mA}$; panel $(\mathbf{b})$ reports the results at $I=1.25 \mathrm{~mA}$.

Figure 10a,b resume the same data, expressed in terms of yield $\left(\mathrm{y}_{\mathrm{AR}}\right)$, evaluated as ratio of absorbance values, related to AR produced over DRN removed, and grouped according to the two levels of $C_{0}$. The results of the RUN 9 at $2.5 \mathrm{~mA}$ have also been displayed in Figure 10b, having been obtained at a high level of $C_{0}$. 

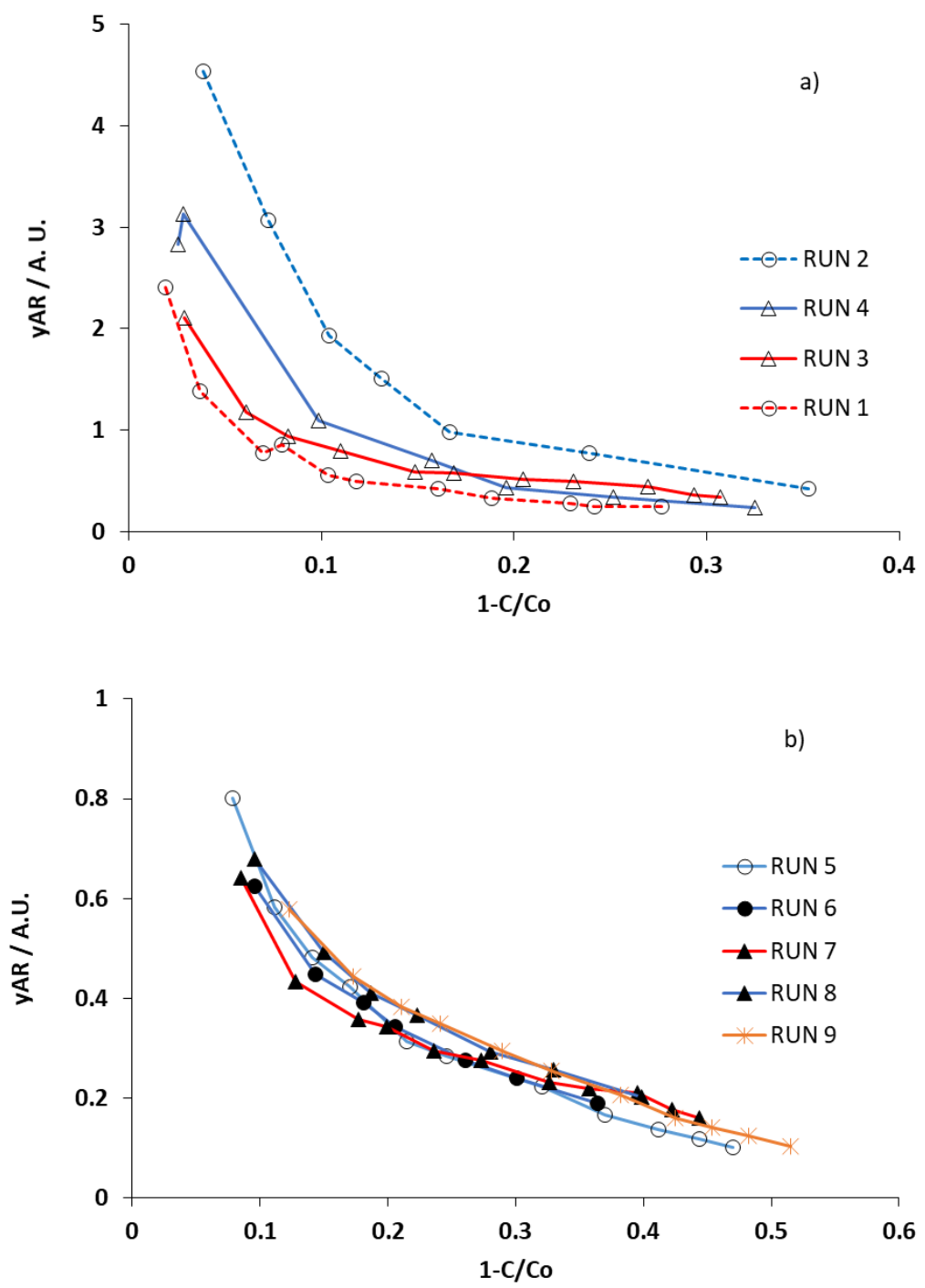

Figure 10. Values of yield of AR formation as a function of the removal of DRN obtained for the eight runs: panel (a) reports the results at $C_{0}=10 \mathrm{ppm}$; panel (b) reports the results at $C_{0}=20 \mathrm{ppm}$.

Although arbitrary units, some indication can be derived from the reported trends of data. The graphs highlight a combined effect between $C_{0}$ and $E$ : in fact, $E$ has a different effect, depending on the $C_{0}$ level. In particular, the conversion of the reactant being the same, if we work at a low level of $C_{0}$, AR accumulates at the greatest extent in solution when a higher $E$ is measured; on the contrary, the potential seems to have no effect when solutions with a high level of $C_{0}$ are processed (Figure 10b): potential values between $0.5 \mathrm{~V}$ and $5.5 \mathrm{~V}$ are measured in this case, but the related curves are overlapped.

The comparison between the trend of intermediates produced, and reactant removal (see Figure 2), may be useful to derive information on the role of the different parameters on the reaction mechanism. Certainly, the potential is paramount when we consider that the reaction can be mediated by the -OH radicals, as generally occurs in similar systems. Under this condition, the reaction occurs mainly in the solution bulk, in the reaction zone immediately adjacent to the electrode surface, where a high concentration of $\cdot \mathrm{OH}$ radicals may exert the oxidative action before they decay. The positive effect of the applied current agrees with this hypothesis: the higher the applied current, the higher the production of $\cdot \mathrm{OH}$ radicals.

However, applied current being the same, depending on the superficial conditions of the electrode, and on the equilibrium with the redox species in solution, the polarization of the electrode can be 
different: to maintain the level of current, a different cell potential can be required, which, in turn may favor different concentrations of $\cdot \mathrm{OH}$ radicals, to be formed.

Thus, for example, for runs R1 and R3, the low levels of $I$ and $C_{0}$ allow the process occurring at very low values of $\mathrm{E}(\mathrm{E}<0.3 \mathrm{~V})$ : the slow reactant removal observed could be attributed to the fact that the electrode is working in the ohmic zone of the semiconductor, the recombination of the photogenerated charges is still quite high, because the depletion is not extended to all the space charge: the observed effect of the potential may indicate that the formation of $\cdot \mathrm{OH}$ radicals is a limiting factor. If the concentration of $\cdot \mathrm{OH}$ is low, then the transformation of the intermediates is not fast, therefore they tend to accumulate in solution (the maximum of AR is measured since the DRN conversion levels are lower than $5 \%$ ).

Instead, when we work at high level of $C_{0}$, the electrode is more polarized (even at the low current, the potential was at least equal to $0.5 \mathrm{~V}$ ): the same value of current may be sustained by different values of potential (this corresponds to the plateau in the polarization curve). In the runs with a high level of $C_{0}$, values of $\mathrm{E}=0.5$ to $5.5 \mathrm{~V}$ were recorded.

The obtained results indicate that, in such conditions, the potential is sufficient to activate the production of $\cdot \mathrm{OH}$ radicals at such a concentration that they are no more limiting for either the oxidative process (the decrease of the reactant is poorly influenced by the E), nor the oxidation of AR, which, indeed, accumulate to a lesser extent in solution.

\section{Materials and Methods}

$\mathrm{TiO}_{2}$ nanotubular structures have been obtained through a well-established procedure $[27,28]$. In brief, titanium disks ( $99.7 \%$ metal basis, Sigma-Aldrich, Missouri, United States), were anodized in a two-electrode cell (see Figure 11A): the exposed geometrical area of the anode was $13.5 \mathrm{~cm}^{2}$, located at $1 \mathrm{~cm}$ distance from a platinized Ti grid, which constituted the cathode. Samples were anodized for $4 \mathrm{~h}$ at $20 \mathrm{~V}$ in solution with $0.14 \mathrm{M} \mathrm{NH}_{4} \mathrm{~F}$, in glycerol-water $(90 \%-10 \%$ vol, respectively): the potential was varied, with a scan rate of $100 \mathrm{mV} \mathrm{s}^{-1}$, from open circuit voltage (OCV) to the final value. Sonication of the samples was made prior to the electrochemical oxidation, in acetone, isopropanol and methanol, (10 min in each solvent); samples were rinsed with deionized water and dried in a Nitrogen stream and, finally, annealed in air atmosphere at $400{ }^{\circ} \mathrm{C}$ for $1 \mathrm{~h}$, in order to transform the amorphous structure into a crystalline one. An example of the final nanotubular structure used in this work is shown in Figure 12.

The synthesized samples constituted the anode in the two-electrode cell (Figure 11B), used for the photo-electrochemical studies. In this case, the cathode was a Pt ring, located in the inner surface of the cylindrical body, to avoid possible shadow on the working electrode. Irradiation of the samples was made, through a quartz window, using a $300 \mathrm{~W}$ xenon lamp, placed at $8 \mathrm{~cm}$ distance, equipped with air mass (AM) 0 and 1.5 D filters to simulate the solar irradiation (Lot Oriel, Darmstadt, Germay). The cell was inserted in a hydraulic circuit (Figure 11C) in which the electrolyte $(\mathrm{V}=75 \mathrm{~mL}$ ) was pumped by a peristaltic pump from the reservoir to the cell and back in a closed loop. Electrochemical tests were performed using a potentiostat-galvanostat (Metrohm Autolab 302N, Metrohm, Herisau, Switzerland), controlled by NOVA software. Minitab software (developed by Pennsylvania State University) was used to perform the DoE analysis.

Removal of DRN was investigated by performing galvanostatic electrolyses of aqueous solutions using $0.1 \mathrm{M} \mathrm{NaClO}_{4}$, as supporting electrolyte. The experimental conditions, planned by a $2^{3} \mathrm{FFD}$, are resumed in Table 1. Each run was started after $30 \mathrm{~min}$ in the dark conditions to allow reaching the adsorption equilibrium of DRN on the electrodes surface. 

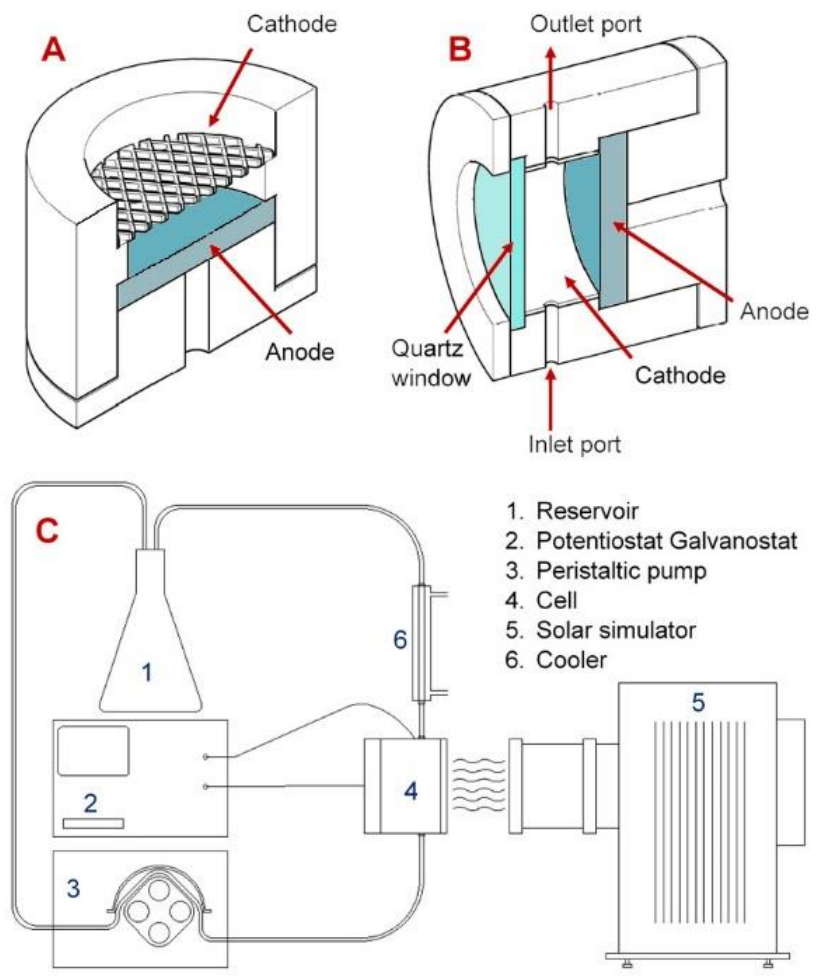

Figure 11. Axonometric sections of the cells used in anodization (A) and in photo-electrochemical tests (B); sketch of the apparatus used for photo-electrochemical experiments (C).

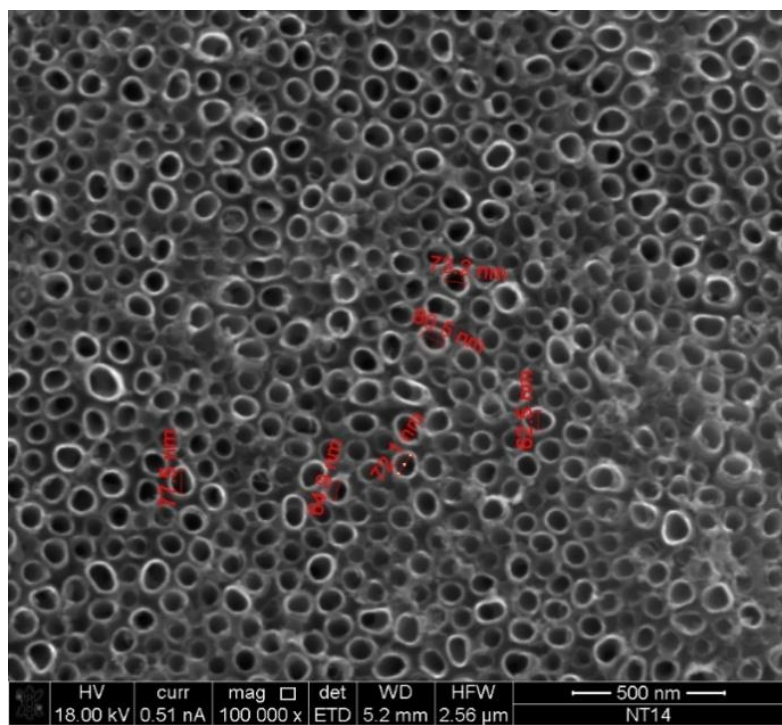

Figure 12. SEM image of the nanotubular structure used as anode in the photo electrochemical cell. A mean tube diameter of $70 \mathrm{~nm}$ was calculated for this sample.

During the runs, samples were analyzed for the concentration of reactant and products by UV-Vis spectrophotometry (Agilent Technologies Cary Series Spectrophotometer, California, United States). Depending on the runs, specific analyses were also performed by high pressure liquid chromatography (HPLC, Waters, Massachusetts, United States) equipped with column Varian (California, United States) C18 with an UV detector (280, 250 or $210 \mathrm{~nm}$ ); mobile phase: Acetonitrile and $0.1 \% \mathrm{H}_{3} \mathrm{PO}_{4}=30: 70$; flow rate: $0.8 \mathrm{~mL} \mathrm{~min}^{-1}$ ). Chromatographic peaks were identified by comparison with pure standards. 


\section{Conclusions}

In this work, we discussed the behavior of raw $\mathrm{TiO}_{2}$ nanotubes during the photo-electrochemical oxidation of diuron, selected to represent the class of herbicides, often present in wastewaters.

Different operative conditions have been investigated, in a planned $2^{3}$ full factorial design. The kinetics of the removal process of reactant has been quantified: specific rate constants in the range from 15 to $33 \times 10^{-4} \mathrm{~min}^{-1}$ were measured, along with cell potential from 0.2 to $2.3 \mathrm{~V}$, which was established during galvanostatic electrolysis.

The results show that the applied current has a paramount effect on both the objective functions (specific rate constant $K$, and electrical potential $E$ ); however, such an effect, which is positive from the point of view of the analysis, results as the opposite for the two objective functions: as we expected, high currents go to the right direction, maximizing $K$, but determine an increase in the cell potential, which instead should be minimized. The analysis also allowed modelling the dependence of the specific removal rate of diuron and the cell potential on the three parameters applied current $I$, electrolyte flow rate $Q$ and initial reactant concentration $C_{0}$. The presence of combined effects, along with the inclusion of the central point responses, indicated that a non-linear model could be more suitable to describe the complex system. However, some useful information has been derived which may constitute a good starting point to a further investigation: an optimal point should be individuated in the response surface, located in the central zone of the investigated parameters, where $K$ and $E$ seem to present a maximum and a minimum, respectively. However, depending on the aim of the process, the reaction path should also be considered.

In this regard, investigation is still ongoing to individuate the intermediates and the final products of the reaction, but from the initial results presented in this work, it appears that the investigated parameters may exert different effects, even on the distribution of the reaction products.

Thus, for example, the applied current-which was of paramount importance for the two objective functions-does not seem to be the most important factor in the distribution of the aromatic intermediates originated during the reaction; actually, in this case, the initial concentration of diuron and the electrode potential seem to play a more important role.

Author Contributions: A.V.: Conceptualization, review and editing; S.P.: Conceptualization, Validation, writing original draft and editing; L.M.: Investigation, visualization, review and editing; M.M.: Conceptualization, review and editing; E.M.U.: Investigation, formal analysis, review and editing. All authors have read and agreed to the published version of the manuscript.

Funding: This research received no external funding.

Acknowledgments: The authors thank Marco Paderi for his support in the experimental work.

Conflicts of Interest: The authors have no conflict of interest to declare.

\section{References}

1. Moreira, F.C.; Boaventura, R.A.R.; Brillas, E.; Vilar, V.J.P. Electrochemical advanced oxidation processes: A review on their application to synthetic and real wastewaters. Appl. Catal. B Environ. 2017, 202, $217-261$. [CrossRef]

2. Särkkä, H.; Bhatnagar, A.; Sillanpää, M. Recent developments of electro-oxidation in water treatment-A review. J. Electroanal. Chem. 2015, 754, 46-56. [CrossRef]

3. Cao, D.; Wang, Y.; Zhao, X. Combination of photocatalytic and electrochemical degradation of organic pollutants from water. Curr. Opin. Green Sustain. Chem. 2017, 6, 78-84. [CrossRef]

4. Garcia-Segura, S.; Almeida, L.C.; Bocchi, N.; Brillas, E. Solar photoelectro-Fenton degradation of the herbicide 4-chloro-2-methylphenoxyacetic acid optimized by response surface methodology. J. Hazard. Mater. 2011, 194, 109-118. [CrossRef]

5. Polcaro, A.M.; Mascia, M.; Palmas, S.; Vacca, A. Electrochemical degradation of diuron and dichloroaniline at BDD electrode. Electrochim. Acta. 2004, 49, 649-656. [CrossRef] 
6. Serpone, N.; Artemev, Y.M.; Ryabchuk, V.K.; Emeline, A.V.; Horikoshi, S. Light-driven advanced oxidation processes in the disposal of emerging pharmaceutical contaminants in aqueous media: A brief review. Curr. Opin. Green Sustain. Chem. 2017, 6, 18-33. [CrossRef]

7. Mais, L.; Vacca, A.; Mascia, M.; Usai, E.M.; Tronci, S.; Palmas, S. Experimental study on the optimisation of azo-dyes removal by photo-electrochemical oxidation with TiO2 nanotubes. Chemosphere 2020, 248, 125938. [CrossRef]

8. Bessegato, G.G.; de Almeida, L.C.; Ferreira, S.L.C.; Boldrin Zanoni, M.V. Experimental design as a tool for parameter optimization of photoelectrocatalytic degradation of a textile dye. J. Environ. Chem. Eng. 2019, 7, 103264. [CrossRef]

9. Hoigné, J.; Bader, H. Rate constants of reactions of ozone with organic and inorganic compounds in water-II. Dissociating organic compounds. Water Res. 1983, 17, 185-194.

10. Andreozzi, R. Advanced oxidation processes (AOP) for water purification and recovery. Catal. Today 1999, 53, 51-59. [CrossRef]

11. Daghrir, R.; Drogui, P.; Robert, D. Photoelectrocatalytic technologies for environmental applications. J. Photochem. Photobiol. A Chem. 2012, 238, 41-52. [CrossRef]

12. Georgieva, J.; Valova, E.; Armyanov, S.; Philippidis, N.; Poulios, I.; Sotiropoulos, S. Bicomponent semiconductor oxide photoanodes for the photoelectrocatalytic oxidation of organic solutes and vapours: A short review with emphasis to TiO2-WO3 photoanodes. J. Hazard. Mater. 2012, 211, 30-46. [CrossRef]

13. Zhang, Y.; Xiong, X.; Han, Y.; Zhang, X.; Shen, F.; Deng, S.; Xiao, H.; Yang, X.; Yang, G.; Peng, H. Photoelectrocatalytic degradation of recalcitrant organic pollutants using TiO2 film electrodes: An overview. Chemosphere 2012, 88, 145-154. [CrossRef]

14. Zhou, X.; Zhou, S.; Feng, X. Optimization of the photoelectrocatalytic oxidation of landfill leachate using copper and nitrate co-doped TiO2 (Ti) by response surface methodology. PLoS ONE 2017, 12, e0171234. [CrossRef]

15. Pan, L.; Liu, Y.; Yao, L.; Ren, D.; Yao, L.; Ren, D.; Sivula, K.; Grätzel, M.; Hagfeldt, A. Cu2O photocathodes with band-tail states assisted hole transport for standalone solar water splitting. Nat. Commun. 2020, 11, 318. [CrossRef]

16. Liang, X.; Cao, X.; Sun, W.; Ding, Y. Recent Progress in Visible Light Driven Water Oxidation Using Semiconductors Coupled with Molecular Catalysts. Chem. Cat. Chem. 2019, 11, 6190-6202. [CrossRef]

17. Garcia-Segura, S.; Brillas, E. Applied photoelectrocatalysis on the degradation of organic pollutants in wastewaters. J. Photochem. Photobiol. C Photochem. Rev. 2017, 31, 1-35. [CrossRef]

18. Russo, D.; Muscetta, M.; Clarizia, L.; Di Somma, I.; Garlisi, C.; Marotta, R.; Palmisano, G.; Andreozzi, R. Photoactivated $\mathrm{Fe}(\mathrm{III}) / \mathrm{Fe}(\mathrm{II}) / \mathrm{WO}-\mathrm{Pd}$ fuel cell for electricity generation using synthetic and real effluents under visible light. Renew. Energy 2020, 147, 1070-1081. [CrossRef]

19. Wang, Y.; Zu, M.; Zhou, X.; Lin, H.; Peng, F.; Zhang, S. Designing efficient TiO2-based photoelectrocatalysis systems for chemical engineering and sensing. Chem. Eng. J. 2020, 381, 122605. [CrossRef]

20. Xiu, Z.; Guo, M.; Zhao, T.; Pan, K.; Xing, Z.; Li, Z.; Zhou, W. Recent advances in Ti3+ self-doped nanostructured $\mathrm{TiO} 2$ visible light photocatalysts for environmental and energy applications. Chem. Eng. J. 2020, 382, 123011. [CrossRef]

21. Nandjou, F.; Haussener, S. Degradation in photoelectrochemical devices: Review with an illustrative case study. J Phys. D Appl. Phys. 2017, 50, 124002. [CrossRef]

22. Peixoto, A.L.C.; Costalonga, A.G.C.; Esperança, M.N.; Salazar, R.F.S. Design of experiments applied to antibiotics degradation by Fenton's reagent. In Statistical Approaches with Emphasis on Design of Experiments Applied to Chemical Processes; Silva, V., Ed.; IntechOpen: London, UK, 2017.

23. Montgomery, D.C. Design and Analysis of Experiments, 6th ed.; John Wiley \& Sons Inc.: Hoboken, NJ, USA, 2005.

24. Myers, R.H.; Montgomery, D.C.; Anderson-Cook, C.M. Response Surface Methodology: Process and Product Optimization Using Designed Experiments, 3rd ed.; John Wiley \& Sons Inc.: Hoboken, NJ, USA, 2016.

25. López-Ramón, M.V.; Rivera-Utrilla, J.; Sánchez-Polo, M.; Polo, A.M.S.; Mota, A.J.; Orellana-García, F.; Álvarez, M.A. Photocatalytic oxidation of diuron using nickel organic xerogel under simulated solar irradiation. Sci. Total Environ. 2019, 650, 1207-1215. [CrossRef] [PubMed]

26. Mais, L.; Mascia, M.; Palmas, S.; Vacca, A. Photoelectrochemical oxidation of phenol with nanostructured TiO2-PANI electrodes under solar light irradiation. Sep. Purif. Technol. 2019, 208, 153-159. [CrossRef] 
27. Palmas, S.; Ampudia, P.; Mais, L.; Vacca, A.; Mascia, M.; Ricci, P.C. TiO2-WO3 nanostructured systems for photoelectrochemical applications. RSC Adv. 2016, 6, 101671-101682. [CrossRef]

28. Palmas, S.; Da Pozzo, A.; Delogu, F.; Mascia, M.; Vacca, A.; Guisbiers, G. Characterization of TiO2 nanotubes obtained by electrochemical anodization in organic electrolytes. J. Power. Sources 2012, 204, 265-272. [CrossRef] 